\title{
Lifestyle and Living Physical Activity as a Part of an Active Way of Life in the Czech Republic
}

\author{
Aleš Sekot
}

Masaryk University, Czech Republic

ABSTRACT

An integral part of a reasonable, creative, valuable, and positive way of life is also personal responsibility for individual physical and psychical shape and good health: a sound state of body and soul, freedom from disease, bodily conditions, and a wish for health and happiness. In this context we are increasingly aware of the great importance of sport not only as a part of mass culture, but broadly understood, for individual and social health and wellbeing. Physical activity of people plays an increasingly more important role in scientific interest regarding the way of life of contemporary society, and it is a very important factor in the process of officiating the level of a healthy and active lifestyle, quality of life, and health in general. The indispensable role of physical activity in the course of human life is permanently and scientifically confirmed in the context of the prevention of obesity.

The development of a sedentary life style is the result of a socialization process towards physical inactivity developed in youth and continued into adulthood. At the present we face in our cultural settings an apparent tendency: people are more and more individualized, losing the beneficial impacts of community activities, involved in passive way of life, and lacking proper level of physical activities and active sport. The phenomenon of physical activity has also been considered from the perspective of the EURO-PREVOB project: accenting built environmental as an aspect of way of life. The Czech Republic is, on the level of mass sport, strongly influenced by the existence of new development of the city structure, including fitness centres, bicycling paths, roller-skating stadiums, beach volleyball playing fields, and golf courses. The national support of sport is, nowadays, divided into the support of top sports, performance sports, and new waves in sports (e.g. sports for everyone - for all), sports for school, which are then on the regional level (and by the various sport organizations) subsidized from other sources and, moreover, not coordinately.

KEYWORDS

physical activity, sport, obesity, society, socialization, built environment, nutrition

\section{General situation}

The transformation from an industrial to an information society since the 1960 s, as well as big advances in computer technology, caused "the great wave of change." Significant changes in the composition of the workforce altered the economic and social roles of men and women, but also affected matters of health and attitudes to physical activities and sport (McElroy 2002). As a result of 
political and economic changes that occurred in the Czech Republic two decades ago, all areas of society started to be restructured. Naturally, this process also included public administration having responsibilities for many areas of people's lives, including sport. This new way of "public matters provision" started at the beginning of the 1990s and culminated in the period 2000-2002.

Together with this process, public administration at lower territorial levels started to rapidly constitute a basis for democratic, and even more, civic society. The area of sport, in relation to the public sector, has gone through great changes both in structural and process terms. The relations between the sphere of sport and the public sector are naturally mutual, undergoing gradual changes (Hobzan \& Cikl 2007). To try to contribute to increasing the knowledge of the present day position of sport in the Czech Republic, it is useful to search for relevant relations of municipalities and their policies for various levels of sport. The task is to explain how the situation has developed and what position sport has gained in the Czech public administration and, of course, to discuss the situation of sport, meaning the present position and role of sport activities in different societal and demographic parts of society, too (Kovár 2002).

With respect to the development of the Czech administration and sport during the past two decades, some ultimate facts must be stressed:

1. The year 1989 brought about the disintegration of a uniform voluntary sports organization.

2. The role of state supervision, however, was not newly delegated to any other explicit body.

3. The territorial structure of the state had changed (by dissolving regions) adopting the structural model with strong positions of regions and local municipalities.

4. With respect to sport, the year 1989 marked the disintegration of a uniform sports organization: all sports associations, federations, and sports clubs, which had originally been its members controlled directly from the organization's centre, gained independence and became legal entities.

5. Additionally, large associations that had been dissolved after the Second World War (e.g., Sokol), and whose members had to merge with all their property with the Czechoslovak Sports Association at the end of the 1950s, renewed their activity.

6. The voluntary sector started to follow the path towards a status that had existed for many years in the West European countries, or in the former Czechoslovakia before 1948. The bodies in this sector became non-governmental, non-profit, independent voluntary organizations with the status of legal entities.

The emancipation process of sports bodies at the beginning of the 1990s, however, also resulted in the necessity of tackling numerous problems related not only to these entities themselves, but also to their relation to the all-society environment. Still, however, advisory bodies as well as professional sections gradually started to work there by dealing with the national representation of sports, sport for all, research, etc. Sport, as it was, was not regulated by any legal code, not even in relation to municipalities. It was up to the municipalities themselves whether they would integrate the sport sector into their policies at all. The voluntary sector, which until then had stabilized and was looking for partnership and cooperation within its own ranks, also participated in these activities by taking the role of a partner. But the continual deficiency of conceptual work on the field of balanced position of leisure and top levels of sport is still typical for relevant politics in the Czech Republic (Slepičková \& Staněk 2007).

On the level of mass sport, the Czech Republic is strongly influenced by the existence of the new development of city structure including plenty of administrative buildings, shopping facilities, fitness centres, cycling paths, roller-skating stadiums, beach volleyball playing fields, and golf courses. The authority for the implementation of the decisions with reference to sport policy and its evaluation is usually delegated to the municipal Department of Education and Culture, with one specialized staff person responsible for sport, and to the Department of the Environment, which is in charge of the reconstruction and maintenance of sports facilities owned by the municipality. 
In some city districts in Czech cities, the strategy in relation to sports facilities focuses mainly on the reconstruction of those situated by primary schools, which are considered a major basis for the development of sport. The utilization of these facilities applies the same rules set by the local administration, preferring long-term hiring contracts by local sports organizations. The chief deficiency, acutely felt by the local administrations in the Czech republic in general, is the absence of swimming pools, the construction of which is planned usually within three years.

Playgrounds of the city districts are usually administered by the Department of the Environment through an authorized staff person who monitors the condition of these playgrounds in terms of physical condition and functionality. Outdoor facilities are all provided to the public for free. In indoor spaces, the schools must respect the local administration regulations concerning the calculation of the prices for hire: costs and resulting prices for hire calculated on this basis are submitted for approval by the council on a half-year basis.

In general, the approaches of municipalities in the Czech Republic to sport show many differences. The causes of the identified differences and, in particular, of a totally different approach to policymaking, therefore, must be sought elsewhere. In the different approaches to sport the political bias of elected and decision-making bodies of the municipality is reflected by the degree of personal enthusiasm for sport of the persons who have decision-making authority in the municipality. It is evident that in municipalities differing by geographical position and appearance, the number of inhabitants, socio-economic characteristics, and economic development. But the evidence is that sport policymaking is not yet a common standard (Slepičková \& Staněk 2007).

To summarize the situation of sport versus local authorities in the Czech Republic: the financial limitations and political priorities play very important roles, as well as professional competence and personal preferences of particular councilors. The approach of the individual town areas to sport is very different, and there are often original public policies in this field. A very diverse approach is also seen in the field of maintenance and development of the sports infrastructure and its utilization. In almost all parts of the Czech Republic, the great importance is on renovation of school facilities. However, access of the general public to the sport facilities often collides with the clearly commercial use of the facilities (Staněk \& Flemr 2007, pp. 294-297).

\section{Some research data on physical and sportive activity of Czech population}

The existing whirlwind of changes associated with way of life and standard of living regarding working activities, nutrition, housing, environment, transport, leisure, and traveling, etc., have had, without doubt, a strong impact on a physically active lifestyle.

We live in the cultural setting adoring youth, beauty, healthy and sexy bodies, and physical performance. Unfortunately, images of fit, healthy, and attractive personalities, as well as widely circulated health messages, have not translated effectively into increased physical activity for most Czech people. Findings from a number of large-scale surveys point to the aversion or the inability of most Czech people to participate in regular amounts of physical activity. Rather, sportive activities are more or less the manifestation of an "up-to-date" lifestyle, than an integral part of everyday life. For the increasingly financially prosperous person in a good social position, sportive activity is the expression of prosperity and the ability to spend freely and independently choose their leisure.

People prefer, in general, passive forms of leisure, watching sport rather than doing sport. Overweight adults being deficient in good physical condition are putting themselves at risk for disease and disability. Medical expert predicted properly that with the declines in physical activity, the current generation of Czech children would grow into the most obese generation of adults in Czech history. Sedentary living has beset contemporary Czech society, identical to the U.S. and numerous European societies, too. In such a situation, we are more and more confronted with pressing questions: "Why do people who know they should be more physically active still fail do so? What form the obstacles to 
achieving a more physically active lifestyle? And very pragmatic question is brought up to date: Is it in sedentary postmodern virtually oriented life possible to transform contemporary people into a more physical active society? What is the real prospect of our endeavour to create a social structure more conductive to a healthier society? Is it possible to overcome persistently questioned limitations found in many of the traditional approaches to promoting physical activity? Are we able to work effectively on the way of innovative strategy to increase physical activity at home, at school, and within the community?" (Sekot 2008).

Regarding systematic, representative sociological research of physical activity - and, consequently, a social analysis of inactivity and patterns of sedentary living - in the Czech Republic, we can summarize: besides some partial surveys of leisure activity of the young generation, there exists representative research of the position of sport and sportive activities in the Czech population. One very representative project - with a random sample of 952 respondents older 18 years of age was organized by Charles University in Prague. Research confirmed very high levels of prestige of sport and sportive activities in Czech society (Slepička \& Slepičková 2002). But at the same time, the research confirmed the generally known fact that a significant part of the population, regarding its positive attitude to physical activities, does not realize the form of regular sport activities in personal, practical, everyday life. Only one-third of respondents declared regular sportive activity at least one time during a week; one-fifth of respondents are involved in sport irregularly and by chance. Seventy percent of Czech people are not associated in sport organizations. On the decline is also positive opinion that accents the importance of mass sportive activity. The presented research has not only been interested in the opinion of the Czech population on the role of sport for contemporary people, but was also searched for existing interest in alternative sports, prevailing barriers to active sporting, accessibility to sport facilities, and the level of passive and active interests regarding sport. A fundamental topic, the general importance of sport and physical activities for the Czech population, is in the aforementioned research reflected in answers that reflect a very high level of positive importance of sport for individuals and society. The highest importance is connected with positive contribution of sportive activities for health, fitness, well-being, and social prestige. Such an attitude also reflects high value acknowledgement and credit for the health for all generations of the population. At the same time the impact of sport as an indispensable factor of socialization is growing, notably as a form of meaningful ways of leisure. The results also reflect an existing discrepancy between positive attitudes towards sport and the conviction to be more intensively involved in active sport (Slepička \& Slepičková 2002, p.15). The presented structure of attitudes towards sport activities reflects the given social and cultural situation in the post-reformation Czech setting: people are not consistent enough to overcome their laziness, are much too busy, too involved in everyday economic problems, neither properly appreciate nor enjoy the refreshing impact of regular physical activities to compensate for the many-sided stress of societal life. But we also take into account the fact that people are prone to declare an absence of leisure as a substitutional reason. Regarding the future role of sport, respondents declared prevailing, widely skeptical opinions reflecting the existing process of the growing disparity between top elite professional sport and mass recreational sport. Such process also supports the consumerist nature of contemporary sport in general. The most frequent reason for sportive activities of men is improving their physical condition, body shape, and societal prestige. Women are more skeptical in reference to their chance practice of regular recreational sport: they complain of the absence of leisure, financial potential, and organizational obstacles.

The relatively positive perception of the physical condition of respondents is reflected in the declaration of frequency of sport activities: one-third of respondents declare active sport activities at least once a week (37\% of men, $29 \%$ of women). Women are doing sport activities less regular $(22.7 \%)$ in relation to men $(14.6 \%)$. Women are also more frequently absolutely physically inactive then men.

Presented data reflect in the Czech population the growing tendency of passive attitudes to sport. Physical inactivity is justified with the absence of leisure, the absence of meaningful motivation, 
and the existence of healthy problems. Of the respondents, $40 \%$ of the "programmatic physically inactive" acknowledge a substantial aversion to physical activity, $28.5 \%$ declare health problem, and $20 \%$ an absence of leisure. Only marginally declared is the absence of sport facilities and financial obstacles (Slepička \& Slepičková 2002, p. 19-21).

Relevant recommendations regarding physical activities in the Czech context accent the need to prepare and to realize self-contained programs for active recreational sport for all groups of the population and within scholastic physical education programs that contribute to a lifelong interest in active physical activities (Frömel \& Bauman et al. 2006, p. 21). In addition, it is necessary to mention that two hours of physical education per week for pupils and students is resolutely not enough. Also, young people are recommended to have active participation in tourism, recreation, and sport as the foundation of physical culture. Physical education in its humanistic version is understood as "an education of man for the care of the body".

Another representative research of 5825 respondents monitoring physical and sportive activities, "Physical activity of men and women 18 to 55 years old in the Czech Republic," reveals that men in all age categories show more days of physical activity than women, as well as a decrease in frequency of general physical activity with age. Only in walking are women in all age groups more active than men. In general, an apparent decrease of walking in the course of aging is evident. A sedentary way of life, as measured by time spent in sitting daily, is more typical for women. It is concluded that the Czech population is not engaged in vigorous physical activity, which promotes the development and maintenance of proper physical shape. To be engaged, preferably daily, in moderate physical activity for at least 30 minutes per day, is unfortunately only a recommended imperative, not reality. As a consequence of such findings, a higher level of intensive and moderate physical activity for both men and women and a lower average period of sedentary time is, for the general Czech population, strongly recommended (Frömel et al. 2004, p. 173). From the perspective of leisure time activities it is evident that, in the Czech Republic, physical activities are much more important in the life of children and young people than in adults. More boys than girls devote themselves to organized sports, even though in recent years the number of girls participating mainly in non-organized forms of physical activities has increased. Of the respondents, $42 \%$ of the boys and $34 \%$ of the girls are engaged in all existing organized forms of sport; $30 \%$ of young people are interested in the subculture of "new sports," including adventure activities, which are becoming more popular than the traditional ones. But the high percentage of young people who do not practice any sport is alarming because of the prognosis of the possible appearance of health risk factors.

Participation in sport and physical activities according to gender, age, and forms of sport shows that Czech boys in all observed age categories (9-24 years) participate in intensive and moderately intensive physical activity more days in a week than do girls. These differences continue with the increasing age of both genders. The average daily time for intensive physical activity for boys is 51 minutes and 33 minutes for girls. But no remarkable differences in so-called "walking days" between boys and girls were registered (Rychtecký 2007, p. 205).

Frequency of participation of Czech males in competitive, organized, highly intensive sport is most evident in the age group 9-11 years (27\%, strong enthusiasm regarding sport career), boys 12-13 years old are most involved in intensive sports and physical activities, 9-11-year-olds are also nonparticipants in physical activities (32\%). Girls are most involved in intensive sportive activities in the age group 16-19 years (32\%), the most passive attitudes regarding physical activities are typical for 911-year-old girls (Rychtecký 2007, pp. 203-204) as a reflection of daily and weekly habitual order and social influences.

To participate in physical activity is a complex problem. One of the most important aspects of such phenomena is the problem of motivation for a sport activity. An investigation of 956 Czech young people 15-24 years of age with regard to their attitude to physical activities was recently conducted. The research covers both young people doing sport and those who are not doing sport. The 
main reasons for going into sport for boys are sharing leisure with friends (28.4\%), to look good, and to improve health; for girls, to look good (25\%), to share leisure with friends, and to improve health (Sekot 2006, pp. 156-158). It is in the logic of the problem that aesthetics and healthy reasons for physical activities are more typical for girls and in sport clubs unregistered respondents.

Parallel research into health behavior revealed risk factors of young people's lifestyles. From the point of view of frequency of physical activities, only one-third of Czech students spend 3 times a week with demanding physical activities, whilst on the contrary one-fourth of respondents spend 1014 hours daily sitting (28.6\%, nursing school students); the same number walk less than one hour per day (29.3\%, grammar school students). In general terms, the results confirm present way of spending free time for young people - with a lack of motion and with a number of syndromes of an organism insufficiently loaded or overloaded in the wrong direction (pains in a back, joints, etc.). Activities for healthy promotion have to be implemented informally, which means moving from filling in forms at schools to concrete health supporting activities: "These activities mustn't be only single ones: they must have long-term and continuous character" (Ř́hová 2007, pp. 137-138).

In the Czech context, a higher level of decentralization and a competent transmission of regional autonomy are needed. To do such tasks, we need to monitor the interest of physical activities in different age groups, evaluate physical fitness levels not only in children and youth, but also in the adult population and elderly people. It means improving chances for regular whole life physical activities, material outfit, preparation of specialists, the realization of long-term education among coaches and instructors, and the fundamental increase of financial support for mass sport from the state. Sport for all must be an integral part of future relations amongst sport, health, education, and socialization. Recommendations to sport organizations for the systematic promotion of physical activities need the full support of local, regional, and national public authorities:

- to develop a membership strategy to include physically passive persons to sportive activities,

- to specify the profile target of sport clubs with accordance with a focus on elite and competitive sport or recreational leisure sport activities,

- to improve coach and trainer standards of an inclusive social and pedagogical climate,

- to accent natural, outdoor activities as grass roots centres for mass involvement in physical activities,

- to ensure and to enable high educational and pedagogical standards of voluntary and semiprofessional staff on sport clubs.

Although prospects for the revitalization of a physically active society are questionable, we are obliged to change or modify a long-standing resistance to exercise among our contemporaries. A post-industrial (or) post-modern society characterized by an involvement in momentary, short-term experiences, refusing traditional and long-term values, is not a good place or cultural context for a transformation to physical activity, either at the societal or individual level. Such transformation will be filled with false starts and obstacles, facing innumerable barriers. These barriers (except the general ones such as inborn individual laziness and indolence) range from political and legislative opposition, a struggle for limited resources with other health concerns, media indifference, and social explanations for our physical activity problems. Public policy makers give insufficient attention to public and health preventive medicine and healthy lifestyles. We live in a situation where most people agree that healthy lifestyles are a fundamental good for individuals and society. But sedentary lifestyle impose many another costs and negative impacts on people not themselves directly engaged in risky health behaviors. Smoking and the sedentary lifestyle of one member of the family could induce emotional stress for the rest of the family, or may cause individual financial hardship related to loss of job or overwhelming medical costs. From a strictly economical point of view, sedentary lifestyles that cost billions in healthcare funds and lost wages contribute to an economic drain on society as a whole. Another problem is related to the question of how far the national physical activity agenda can go in regulating personal behavior: people do not want to be told what to eat, what to drink, and how much to exercise. Anyway, our chance to achieve a physical active society could be improved if we could 
overcome the challenges of truly healthy lifestyles available to all members of society, or at least for most part of society.

\section{Urbanization versus sport facilities}

The phenomena of physical activity and sport is closely related to the urbanization of sports facilities. In such a context it is useful to describe and analyze the most important milestones in the history of city planning (urbanization) in the area of sport facilities. Comparisons of the development of sport facilities in ancient times with the current equivalent status seem to be rather negative. Further, it is the paradox that the low quality of urban planning nowadays is particularly reflected in the suburban areas of Prague, where the public infrastructure (sport facilities included) does not reach a sufficient level. Rapid housing and industrial development in these parts of the city has, unfortunately, overtaken the local development framework, resulting in numerous urban-architectural and, moreover, sociological issues. Sport facility planning, creation, development, and management should be considered to be one of the strategic points in public administration on both the local and state level (Flemr 2007, pp. 93-105).

The very beginning of the modern sport facility - formerly the playgrounds - is illustrated in the 18th century as a consequence of the sport movement in England as well the philanthropic movement in Germany. The simple, separate playgrounds had been constructed with respect to spectators in the context of the growing popularity of spectator sport, mostly for tennis and athletic and football stadiums. In Scandinavia indoor facilities were also constructed in the beginning of the 18th century. In Czech history the first real gymnasium was launched in 1862 - the Malypetr gymnasium, used by the Gymnastic Association of Prague. The last decade of the 19th century brought out strong practical incentives for school and public gymnasiums and subsequent sportive facilities. At the beginning of the 1890s, about 500 tennis courts were in operation in the Czech countries. The late 19th and early 20th centuries improved public mass interest in football and biking. Strong incentives for mass sportive activities were connected with the existence of the Sokol movement and the modern Olympic games beginning in 1896 .

The formation of an independent Czech Republic in 1918 entailed a strong impulse for building new sportive facilities, notably those for ice hockey, football, and gymnastics. An advisory committee for physical education was established in 1920, coordinating a conception for building new sportive facilities, for youth in particular. Despite this endeavor, only $11.3 \%$ of elementary schools had their own gymnasium, $45.3 \%$ exercising grounds or courtyards. Better situations were found in secondary and high schools: $75 \%$ of them possessed gymnasia (Flemr 2007, p. 95).

Socialist planning accented unified physical education and sport. In the Czech Republic during late 1940, 1250 gymnasiums, four indoor $25 \mathrm{~m}$ swimming pools, and one indoor ice hockey stadium were centrally operated. A growing accent on mass physical educational activities and sport brought around building new sportive complexes, some of them of very low technological quality. The Czech association for physical education, beginning with its launch in 1957, had been a chief agent for purposefulness of sportive facilities.

Up to the early 1990s, the theoretical, urban value of a sportive space for one single inhabitant was $17 \mathrm{~m}^{2}$; nowadays, the exercise space for one inhabitant is $5.09 \mathrm{~m}^{2}\left(1.99 \mathrm{~m}^{2}\right.$ for an organized sport, $1.79 \mathrm{~m}^{2}$ for school physical education, $1.31 \mathrm{~m}^{2}$ for unorganized sport); the usable exercise space for one inhabitant is $7.24 \mathrm{~m}^{2}\left(2.88 \mathrm{~m}^{2}\right.$ for organized sport, $2.22 \mathrm{~m}^{2}$ for school physical education, $2.14 \mathrm{~m}^{2}$ for non-organized sport). Municipal sportive institutions are basically not profitable - no wonder that investors prefer to invest in commercial sportive facilities. It is reflected in the rather neglected situation of mass recreational and leisure time sport activities in the Czech Republic.

It is generally accented, and in Czech context too, that municipal policy must support the active lifestyles of a very colorful and broad spectrum of the population. Such an objective was strongly 
accented - mostly after 1989 - during the process of European Union integration. Within the European priorities, health issues and active lifestyles of citizens are included. Sport and physical activities represent significant features of those priorities. In such a context, the relevant terminology of this area is elucidated, and the terms such as active lifestyle and public policy are defined. In summary, the current situation in the Czech cities accents the imperative of an active municipal sport policy. But in fact, unfortunately, a rather closely reactive policy has been implemented in the Czech context: while existing problems are mostly solved, future complex interventional programs are rather ignored.

\section{Socioeconomic indicators of physical activity}

Underlying health determinants of a socioeconomic nature play a major role in causing vulnerability to health risks, including obesity. Indeed, a social gradient in obesity has been demonstrated with individuals in lower socioeconomic groups (lower incomes or lower levels of education, or both), thus having a higher risk of being obese and thus suffering from obesity-related diseases. The reasons why these inequalities have arisen and persist include constraints imposed by low incomes and low educational achievement on food choice, opportunities for recreational exercise, and differential absorption of health promotion messages.

People prefer, in general, passive forms of leisure: watching sport rather than doing sport. Overweight adults being deficient in good physical condition are putting themselves at risk for disease and disability. Hlúbik et al. carried out an investigation on obesity in the Czech Republic in 2000. The study monitored 933 volunteers, both sexes and with an age ranges of 19-60 years. Anthropometric parameters such as weight, height, skin fold thickness, and abdomen circumference were measured. BMI and fat tissue percentage were calculated on the basis of gathered data. The authors detected overweight in $67.5 \%$ of the monitored men, obesity in $17.0 \%$ of them; $50.0 \%$ of the women were overweight while obesity was detected in $18.9 \%$ of them. Waist circumference exceeding $102 \mathrm{~cm}$ was measured in $41.2 \%$ of men and waist circumference exceeding $88 \mathrm{~cm}$ in $41.7 \%$ of monitored women (Hlúbik 2000).

Physical activity is a complex behavior. Any activity can be described in terms such as intensity, frequency, and duration, and these dimensions must be considered. An assessment methodology should also consider inactivity, such as time spent sitting. Physical activity can be related to work, transportation, home, and leisure time. The activities in any of these domains may have specific health consequences, and advanced monitoring should also consider these factors. To present the most important results of existing research data it is possible to conclude (Frömel, Bauman et al. 2006):

1. The growing age of population (both men and women) decreases the number of weekdays and volume of time devoted to physical activity,

2. Men in general are more involved in physical activities compared to women,

3. Growing age decreases existing differences in intensity of physical activity between men and women,

4. Medium level of physical activity and walking is distributed in age groups and gender groups relatively evenly,

5. Walking is the most frequent form of physical activity in the czech population,

6. Regular monitoring of level and tendencies of physical activity of the population is an integral part of monitoring the health situation and lifestyle of the population.

The phenomenon of obesity in the context of physical activity is strongly connected with the area of teaching of physical education at a given level of school. One of the most important roles for acquiring proper habits and patterns regarding regular lifelong physical sportive activity play is during primary and secondary school. A research sample of 153 Czech rural pupils aged 11-15 years exposed $20.0 \%$ overweight boys, $9.6 \%$ overweight girls, $2.9 \%$ obese boys, and $1.2 \%$ obese girls. On the contrary, $14.3 \%$ boys and $21.7 \%$ girls were under the commensurate weight (Rýgl 2006). Most 
respondents were interested in collective sportive activities (e.g., ski training, biking, boating). The most popular sportive games for 12-year-old girls are the ball games pig-in-the middle, rugby, floorball, volleyball, and basketball. Boys at the same age prefer floorball, football, rugby, handball, and basketball. Overall results refer to a high level of popularity of physical education comprehended mostly as an explicitly attractive activity. Research in such a context accents the necessity to improve attractive and emotively experienced aspects of physical education to improve a high competence of kinetic physical activities for lifelong body and healthy care. At that time the importance of strict "marking" of sportive performance is not recommended - more attention is focused to support one's individual ability to be regularly involved in physical/sportive activities.

\section{Physical activity versus obesity with perspective of PREVOB Project}

The situation in the Czech Republic regarding obesity is reported as alarming: $21 \%$ of men and $31 \%$ of women are obese (obesity and overweight $=68 \%$ of women and $72 \%$ of men). Additionally, $66 \%$ of men and $54 \%$ of women in the age group 20-65 years are overweight or obese, while "only" $17 \%$ of men and $21 \%$ of women are obese. In children, the overweight rates $7-8 \%$ and obesity $6-7 \%$ (overweight and obesity, in total, 13-15\%). A specific phenomenon of Czech population is the obesity occurrence in all social groups, with no strong differences in some social strata (Šeráková 2007, pp. 814-815, For̆t 2004). Whatever the results on obesity in the Czech Republic are given by the authors, all of them agree on the fact that the prevalence of obesity grows enormously, despite the fact that situation need not be as critical as it is often presented in the media and press (Sekot \& Brázdová 2008).

Health researchers, physical activity managers, and decision-makers are searching for a common methodology in order to assess the extent of development and implementation of selected policy areas on dietary intake, physical activity levels, and obesity throughout Europe. Between autumn 2008 and spring 2009, thanks to support from the WHO Pilot project that tested such matters, five European countries were chosen to represent five sub-regions of Europe, namely Bosnia and Herzegovina, the Czech Republic, France, Latvia, and Turkey. Moreover, sub-regional working groups made up of stakeholders and experts have been organized to review the results of the pilot tests and discuss the relevance and applicability of the Policy Analysis tool within their sub-region Project no. 044291 "Prevention of Obesity in Europe - Consortium of the prevention of obesity through effective nutrition and physical activity actions - EURO-PREVOB” (Derflerová-Brázdová et al. 2010).

The first conclusion regarding the general results of the pilot test in terms of policy in reference to complex documents on obesity, nutrition, and physical activity reflecting the situation in the Czech Republic in general is that they ignore in some respects the phenomenon of inequality. Physical activity policy documents (national and state ones) abstract away from problems of obesity and only marginally refer to phenomena of inequality to participate in regular physical/sportive activities. As a strategy, government/ministry documents promote general education of healthy lifestyles in schools and support construction and maintenance of sporting facilities in the Czech Republic in order to enable regular physical activity for the handicapped, too.

Representative documents retrieved on national and school policies reflect mutually dependent and interconnected topical issues such as nutrition policy, physical activity policy, compulsory nutrition education, free or subsidized school meals, fruit or vegetables, marketing restrictions with regards to foods high in fat, sugar, or salt, restrictions on what items can be sold from vending machines in schools, freely available drinking water in schools, compulsory physical activity education, special physical education for disadvantaged groups or girls, and promoting safe 'walk to school' routes.

Applicability, relevance, and usefulness of this tool for Central Europe is, from the perspective of a policy checklist, partly limited due to the fact that there are limited occasions to obtain and thereafter analyze relevant documents that are mostly very formal and absent criteria of personal or 
institutional responsibility for the realization of declared intentions. Official documents on physical/sport activity are not complex ones: they are rather declarative, with no effective means of monitoring or effectively realizing the main objectives, or directly supporting mass forms of generally accessible physical/sportive activities.

Recommendations for changes are derived from an existing, prevailing, formal nature of processed documents and information. Policy analysis also needs, in some specific situations, individual interviews with relevant persons responsible for the supervision and inspection of fundamental intentions and time intensive tasks of constituent parts of policy tools with regards to nutrition and physical activity.

The perspective of the applicability of the EURO-PREVOB Project community questionnaire reflects the fact that most hypotheses on physical activity versus building environment in this context were not confirmed. As a consequence we conclude:

1. To respect the fact that the number (and respectively the quality) of neighborhoods is reflected in concentration of bicycle paths only indirectly or vicariously: Bicycle paths are intended and constructed primary with respect to suitable natural and terrain preconditions, with no direct and verifiable relation to the cultural and economical nature of given neighborhoods. As a practical consequence, the existence of bicycle paths does not vary by social setting and it does not presuppose a "visibly and tangibly" higher quality of bicycle paths passing through wealthier neighborhoods.

2. With reference to the existence and quality of public open spaces and playgrounds, in the context of rejecting reasonably sounding hypothesis on higher quality in wealthier neighborhoods, it is to remember the existing general high level of vandalism and culturally non-conclusive distinctions in the context of different social and economical strata in most "post-communist countries".

3. The existence and quality of public transport stops reflects the quality of public transport in general and the relevant local social, cultural, and economic situations as well. But it is to say that the Czech Republic (as well as in the sub-region of Central Europe) is very traditionally oriented for an efficient public transport system outfitted with up-to date transport vehicles and compactly distributed network of public transport stops. But in general, the quality of transport stops is first and foremost given by nature of passengers (mostly the lower social strata) in no direct relation to nature of the relevant neighbourhoods.

4. Frequency of traffic volume is an outcome of a few factors or agents: the phenomenon of traffic volume is multi-dimensional and, as such, is not linearly shaped with an immediate social and cultural setting.

5. Sidewalks are public property determined from the perspective of existence and quality with a plurality of economic, technological, social and cultural circumstances not always having exact qualitative and quantitative outcomes.

6. It is useful to respect the fact that in territory of a "post-communist country" (countries) the built environment is not socially and culturally structured enough to reflect visible and tangible attributes of sociologically structured levels of neighborhoods.

The starting point of Czech participation in the EURO-PREVOB project was fundamental information on obesity in the Czech population: $52 \%$ of the Czech population is above accepted parameters. There appears to be a north-south gradient in the prevalence of obesity, with higher BMI reported in towns of the north (mostly inhabited with socially disadvantaged population) of the Czech Republic. Previous epidemiologic studies show that at least $52 \%$ of the Czech population would like to maintain their weight under normal limits and $42 \%$ would like to reduce it, $50 \%$ of those being women. Twenty-three percent of the population affected by obesity is completely satisfied with their own weight (Czech Society for the Study of Obesity). 


\section{PREVOB - physical activity versus built environment}

The aforementioned EURO-PREVOB project summarized important data regarding built environment in the context of chances and limitations for mass physical/sport activities. So we can conclude (Sekot 2010):

1. Active participants and practical users of bicycle paths. Most of them are recruited from social strata characterized with interest in healthy and active life style incorporating regular leisure physical / sport activities. It would be very useful to identify more detailed structure of bicycle paths with respect to intensity of physical/sportive activities. It is supposed that at least two fundamentals categories of bicycle paths users exist:

a) regular users involved in periodical physical/sportive activities as a part of leisure in the context of everyday life,

b) occasional or provisionally "would-be sportsmen" involved in cycling mostly as a part of personal image, practicing cycling predominantly as a social activity without deeper rooting in value orientation containing regular physical/sportive activities as an integral part of everyday life.

A specific feature of the "bicycle path scene" in the Czech Republic calls attention to the growing presence of roller skaters - sometimes and in some routes - exceed half of the given participants. It reflects on the one hand the high dynamics of the popularity of (in-line) rollerskating and, on the other hand, the poor level of official and legal regulation or conception of "game rules" of bicycle paths. Unfortunately - with all respective negative impacts for participants - collisions, injuries, and interpersonal conflicts occur.

Another typical aspect of monitored bicycle paths is their rather "leisure" nature. Bicycle paths are mostly located in suburban or outskirts areas connecting recreational points rather than locations of everyday, practical activities. As a consequence it is not in practice possible to use bicycle paths for travel to work, to deal with civic affairs, or to shop. Bicycle paths are mostly used for one-sided, leisure activities. Good physical and psychical shape, well-being, or personal image are most frequent reasons for to be part of the bicycle path scene; a practical way of everyday active transport is only marginal motive of mass cycling in Czech Republic.

2. Public open spaces as a part of built environment are, from the perspective of their quantity as well from the point of view of their quality, dependent on the fundamental character of given settings. The social, cultural, and economical features of selected areas play very important roles and are also significant preconditions of the appearance of public parks and public playgrounds. Wealthier neighbourhoods provide more parks and playgrounds than socially, culturally, and economically less booming, poor, and disadvantaged or neglected boroughs (or even ghettos). Most striking, the dividing lines or contrasts are visible and tangible between ethnic ghettos (gypsy) on the one side, and prestigious borough on the other side. In reference to public parks, their occurrence as well their quality (maintenance, neatness, service, safety) is incomparably higher in healthy boroughs than the analogous situation in poor neighbourhoods. In this given situation there also exists another feature: in top prestigious "high society" neighbourhoods, inhabited with people living in private family houses, villas, or residences, the existing public parks are not so visited and popular - the local people prefer to stay in the luxury of their houses and gardens or to visit "specific" leisure and public recreational facilities in different or distant places. Most popular are the public parks in good, substantial "middle class" neighborhoods provided in most cases with playgrounds for children. On the contrary, public parks in socially neglected parts of the city are rather small, badly maintained, dirty, and lack proper security. Common problems experienced by most public parks in all neighborhoods are dog excrement and vandalism.

3. Playgrounds - from the perspective of their existence and their quality - vary as a matter of principle in accordance with aforementioned situation in public parks: higher quality exists in 
wealthier neighbourhoods, while neglected and miserably maintained are provided in poor neighbourhoods. A specific aspect of the latter is the high level of vandalism. In some public playgrounds interested people are allowed to enter and use public playgrounds only in presence of commissioned person delegated by the local municipality! Another negative aspect of monitored public playgrounds is the absence of publicly available sportive and fitness equipment and facilities: presumably as a consequence of the apprehension of vandalism. Public playgrounds are in fact in defense against the growing incidence of commercial fitness centres. Such a situation reflects the deepening gap between different social stratums (and quintiles), with negative impacts on quality of life and structure of leisure experienced by the socially lower categories. Striking existences of vandalism, as well as the diffusion of lower social strata into higher quality public parks and playgrounds, result in the generally poor quality of public open spaces in searched localities - public parks and public playgrounds.

4. The existence and quality of public transport stops reflect the quality of public transport in general and the relevant local social, cultural and economic situations, too. It is not primarily the very existence of public transport stops, but the quality, that reflect the nature of given neighbourhoods. Quality, ergo the comfort, coziness, neatness, non-desolated nature, and safety of public transport stops are supposed to be higher in healthier, more substantial, and more secure neighbourhoods: transport stops are secure shelters for passengers waiting for their bus, trolley bus, or tram. Smoking is strongly forbidden on the tram platforms and transport stops. Sometimes, and mostly in the centre of the city, the welcomed appeal for healthcare and the fight against obesity is placed in the transport stops: "Presently the best way to improve your shape is to go to the next transport stop by walking."

The quality (but not directly the existence) of public transport stops in socially disadvantaged city districts is mostly decreased in quality, comfort, and security as a consequence of vandalism, deficient maintenance, and destructive presence of local youth gangs and socially non-adaptable individuals. Local youth also use (disuse) public indoor or roofed transport stops as a place for coming together or as a shelter in situations of bad weather. But, in general, the quality of transport stops is first and foremost given by the nature of passengers (mostly lower social strata) with no direct relation to nature of the relevant neighbourhoods.

5. The frequency of traffic volume, above all else, reflects the dynamic factor of general possession of private and business cars in the Czech Republic and relative mass use of cars for everyday transport to work and for shopping. Suburban areas are strongly affected by truck transport and commuters. Housing estates are affected: mass lodging typical for blocks of council houses are mostly in the vicinity of busy highways and supermarkets. On the contrary, housing estates of higher social class are mostly far - and prevented - from busy and noisy roads, factories, business points, and hypermarkets. The sparse population in private family houses and neighbourhoods benefit in many respects from low and quiet traffic volumes, whilst the high concentration of population using the cars and traffic transport in low social housing estates and in the centre of the city are affected by a busy, noisy, and polluting transport and traffic volume. But it must be taken in account that the phenomenon of traffic volume is a multi-dimensional one, and as such is not linearly shaped with immediate social cultural settings.

6. The quality, durability and the very existence of marked road crossings is reflected in the complex nature of relevant built environment. The quality of road crossings reflects the quality of neighborhoods in general, the maintenance of all public places and buildings, the roads and their marking - equally important for transport security - in particular. Road marking is, in disadvantaged housing estates, mostly destroyed via bad road maintenance of dirty, shattered, and potholed roads. 
7. Sidewalks are an integral part of built environment and, as such, they reflect quality of relevant neighbourhoods. Sidewalks play an important role not only as a reflection of the general quality of given public places, but they are also important for the personal security of local inhabitants and walkers, too. Sidewalks reflect the quality, aesthetics, and security of built environment: they are a visible and tangible demonstration of level of built environment and relevant quality of life, including "ability" to walk. Perfectly maintained private and municipal sidewalks near family houses and mansions areas are strongly dissimilar to the neglected, shabby, and broken sidewalks engaged and occupied with parking cars and soiled with litter, cigarette buts, and aged dirt. But at the same time, sidewalks are public property determined from the perspective of the existence and quality with a plurality of economic, technological, social, and cultural circumstances not always having exact qualitative and quantitative outcomes.

8. It is evident that built environment plays a very important and growing role in the quality and attractiveness of neighbourhoods, including chances and limitations for regular and publically accessible healthy sportive/physical activities. To have or not to have a "good neighborhood" is the fact gaining strength in the post-communist Czech Republic too. The growing social and economic difference in Czech society increases aspect of social inclusion and exclusion, and a "good address or bad address" is an important attribute for attractiveness/unattractiveness of built environment. This plays a more important role in the personal decision-making processes than just the quality and aesthetic attractiveness of a given apartment or house. It works on the level of prestige of a "private address" as well in a "business address." Despite the last decade of "unrestrained capitalism," more attention and more emphasis is at the same time being oriented not only to the level of attractiveness of new housing but just on the quality of more general built environment - living conditions, quality of urbanism, stillness, transport accessibility, security, social structure, existence of schools, public facilities, shopping opportunities, level of air pollution, contact with green nature, and existence of sportive facilities. But it should be remembered that the built environment in a given territory is not socially and culturally structured enough to reflect the visible and tangible attributes of the sociologically structured levels of neighborhoods.

The most critical policy area on physical/sportive activity is the sole fact of the sedentary nature of contemporary society. It is evidently openly and bitterly accented that the development of a sedentary lifestyle as the result of a socialization process towards the physical inactivity developed in youth and continued into adulthood. Social analysis of inactivity and patterns of sedentary living has concluded that in the Czech Republic there are very high levels of prestige of sport and sportive activities in Czech society. But at the same time it confirmed the generally known fact that a significant part of the population, given its positive attitude to physical, sportive activities, does not realize regular physical or sport activities in their practical, personal, everyday form of life. People in the Czech Republic, are in many respects permeated with the busy capitalist rhythm of the "post-transformed society," oriented one-sidedly for performance, success, popularity, money, and societal admiration. In such a milieu, the endangered and problematic groups of a population are busy, stressed, feel the lack of leisure and high amounts of car driving and high technology involved with top businessman, managers and "workaholics," as well as socially deprived groups including jobless people or ethnic minorities (mostly Gypsies) that lack proper value orientation that accents healthy and sustainable lifestyles, which absorb healthy dietary habits, regular intentional physical exercise, as well as sportive and outdoor activities (Slepičková \& Flemr 2007).

It is a priority to develop and pilot suitable flexible tools that will enable public health researchers and decision-makers to assess the potential impacts of proposed policies on dietary intake, physical activity levels, and obesity throughout Europe using a common methodology, 
and to assess the potential effects of the distribution of those impacts within the population (that is, issues of equity and impact on specific vulnerable groups).

\section{General conclusions: What Czech society expects from sport?}

Mutual relations of sport and society are mostly and visibly reflected in the media's top television sport events. In this context we face typical reflection of passive consumerism of sport as an important part of mass culture: people (society) expect from sport top performances exciting shows that compensate for the monotonous course of everyday life. Society has also found in top sport a refreshing source of patriotism and medial celebrities, icons, and heroes as a target of mass admiration in situations regarding their absence in the rest of society (mostly in politics). The existence of the sedentary way of life detracts from the general level of physical/sports activities in the everyday life of the mass of people; the growing importance of an active way of life and human health demonstrate the phenomenon of individual responsibility for human wellbeing. People responsible for his or her good physical and psychical shape expect from sport an indispensable source of wellbeing, respect of their surroundings, and - last but not least - his or her self-respect.

The general framework of our discussion on the mutual relation of sport and society postulates that governmental institutions should search the field of sport for real opportunities for active sportive activities for the older population, and to test relevant situations in self-contained programs for active recreational sport for all groups of population. The real chance for schools to teach physical education is to contribute to a lifelong interest in active physical activities. High levels of political will and leadership are required to achieve a decrease in obesity prevalence. All relevant state sectors and levels should play a role in supporting sport as a form of an active way of life: the new horizons for civil society are outlined here. In mass society the media has an important responsibility in the propagation and dissemination of healthy lifestyles.

To discuss the phenomena of physical activity means, in such perspective, to accent the changing nature of lifestyles and leisure time activities that have adopted new forms, contents, and meanings. The world of sport and physical activities is also changing all the time in numerous new sport disciplines and activities, which are being chosen by a growing proportion of people. It could be expected that these changes would affect also the socialization situations and environments of physical activity:

1. The Czech situation must be prepared for the specific situation of ethnic minorities (mostly the Romani population) that is reflected in the level of their attitude to physical and sportive activity, too. In traditional Romani culture the positive attitude to sport is derived from relevant value attitudes of the majority society. Mostly, the young generation of this minority appreciates sport in positive way, thanks to peers and school education. Despite such positive tendency, only $14 \%$ of gypsy youth are involved in regular sportive activities - mostly in football, jogging, biking, swimming, and dancing (Hastrmanová \& Houdek 2007). Also, the 911-year-old pupils of practical elementary schools are not properly and proportionally involved in extracurricular movement activities. Just $19 \%$ of them participate in organized physical activities, compared with $55 \%$ of children from ordinary elementary schools.

2. The presented structure of attitudes towards sport activities reflects the given social and cultural situation in Czech in a post-reformation setting. People are not consistent enough to overcome their laziness, are too much busy, too much involved in everyday economic problems, do not properly appreciate and enjoy the refreshing impact of regular physical activities to compensate for the many-sided stress of societal life. But we also take into account the fact that people are prone to declare an absence of leisure as a substitutional reason. Relevant data reflected in the Czech population demonstrates a growing tendency of passive attitudes to sport. Physical inactivity is justified by the absence of leisure, by an absence of meaningful motivation, and an existence of healthy problems. Forty percent of the 
"programmatic physically inactive" acknowledge a substantial aversion to physical activity, $28.5 \%$ declare health problems, and $20 \%$ indicate an absence of leisure time. Only marginally is declared the absence of sport facilities and financial obstacles (Slepička \& Slepičková 2002).

3. To present the most important results and information on the tendencies in the field of physical activities means to conclude that the growing age of population (both men and women) decreases the number of weekdays and volume of time devoted to physical activity. Men in general are more involved in physical activities and active transport (cycling, walking) compared to women.

4. Nowadays, physical education is defined as the process that aims to prepare children and young people to participate in physical culture (tourism, recreation, sport). It is also understood as the foundation of physical culture. Physical education in its humanistic version is understood as "an education of man for the care of the body." Humanistic aspects relating to physical education accent intentional activity aimed at forming positive attitudes towards the body, familiarizing a person with the world of physical culture consisting in shaping attitudes towards the body and the values of physical culture, an education for the values of the healthy body, an education of the personality for the care of the body, and for preparing children and young people to take responsibility for their health, fitness and the beauty of the body after completing their education.

5. Social environment consists of the nonphysical products of human interaction, which include the ideas and values shared by members of a particular group as well as they come together to participate. The synergistic roles of physical and social environments affect participation in physical activity. Resulting behavioral settings can promote physical activity when they provide physical space (e.g. sports facilities, health clubs, bicycle paths, swimming pools) along with the social resources that we draw upon to interact with other community-policing programs.

6. The phenomena of physical/sportive activity is many-sided, and is connected with the concept of a healthy lifestyle. Lifestyle behaviors in general are significantly determined by social status, by professional position, by amounts of money, and the quantity of property. Those who have the means may choose to be physically active; those lacking financial resources cannot freely choose to be involved in regular sportive activities. Unhealthy behaviors, including sedentary lifestyles, are influenced by a person's position within social groups and broad social forces in the general society. But the decision about whether to adopt a healthy lifestyle reflects personal attitudes and value preference and thereby includes an aspect of personal choice. But factual personal choice has many preconditions with regard to social position and the cultural quality of people, and with access to resources of the full range of choices regarding sportive activities.

We can conclude: healthy lifestyles are patterns of voluntary behavior based on choices from options that are available to people according to their life situations. In developed postindustrial countries, the members of the upper and middle class, by way of active lifestyle, mostly reflect their values and self-identity, accenting a balanced share of intellectual and physical activities. It is a tendency to evaluate good health as a personal value to be sought and cultivated for one's own benefit, such as experiencing increased vitality and enjoyment of life. Lower-class individuals, with reference to the nature of their work activities and income, are less optimistic to ovoid poor health and thus are less apt to participate in systematic health promoting activity. Anyway, people in lower socioeconomic position experience poorer health and higher disease rates when compared with more privileged social groups.

7. The phenomenon of physical activity and sport is closely related to the urbanization of sports facilities. In such a context, it is useful to describe and analyze the most important milestones in the history of city planning (urbanization) in the area of sport facilities. The rapid housing 
and industrial development is resulting in numerous urban-architectural and moreover sociological issues. Sport facility planning, creation, development, and management should be considered one of the strategic points in public (administration) on both the local and state level (Flemr 2007).

Even the preliminary results of presented research data and pilot studies imply that individual municipal authorities in the pertinent town areas attach diametrically different importance to sport and sporting activities. A large difference is already visible in the management of sport and sporting activities within the organizational structures of the municipal authority. The most critical policy area in physical/sportive activity is the sole factor of the sedentary nature of contemporary society: the very high level of prestige sport and sportive activities in Czech society is incompatible with the very low level of practical, regular physical or sport activities.

\section{REFERENCES}

Derflerová-Brázdová, Z., Schwanhauser, K., Sekot, A., Hruška, D., Sebera, M. (2010). EURO-PREVOB: Dílčí zpráva o spolupráci Masarykovy univerzity jako zástupce České republiky na projektu 6. rámcového programu č. 044291. /Partial Report on Cooperation of Masaryk University as a Reprersentative of Czech Republic in Project no. 044291/. Zdraví, 1, 1-7.

Flemr, L. (2007). Podmínky pro aktivní životní styl dětí perspektivou pedagogů tělesnévýchovy /Preconditions for active lifestyles of children via perspectives of phycical culture teachers/. Aktuální otázky sociologie sportu. Praha: Karlova univerzita.

Formánková, S. (1998). Některé oblasti longitudinálního výzkumu zájmu žáků o pohybovou aktivitu. /Selected topics of long-term research on involvement of school pupils in sport activities/. Celostátní vědecká konference s mezinárodní úèastí v oboru kinantropologie. Olomouc: Hanex.

Fořt, P. (2004). Stop dětské obezitě /Halt to children's obesity/. Praha: Ikar.

Frömel, K. et al. (2004). Physical activity of men and women 18 to 55 years of age in Czech Republic. In F. Vaverka (Ed), Movement and Health (pp. 169-173). Olomouc: Univerzita Palackého.

Frömel, K., Bauman, A. et al. (2006). Intenzita a objem pohybové aktivity 15-69 leté populace České republiky /Intensity and volume of physical activity 15-69-year-old population of Czech Republic/. Česká kinantropologie, $10(1), 13-27$.

Hlúbik, P. et al. (2000). Prevalence of obesity in selected subpopulations in the Czech Republic. Sborník lékařský, 1, 59-65.

Hobza, V., Cikl, R. (2007). Subvenční politiky ve sportu a tělovýchově v České republice /Subvenciolal policy in the field of sport and physical culture in Czech Republic/. Česká kinantrolologie, 2, 67-82.

Kovář, R. (2002). Tělesná aktivita, tělesná zdatnost a zdraví /Physical activity, physical fitness and health/. Česká kinantropologie, 6(1), 49-54.

McElroy, M. (2002). A Social Analysis of Inactivity. Champaign, IL: Human Kinetics.

Project no. 044291 Prevention of Obesity in Europe - Consortium of the prevention of obesity through effective nutrition and physical activity actions - EURO-PREVOB.

Rychtecký, A. (2007). Active Lifestyles of Young People - Benefits and Outcomes. Obesity in Europe. Young People's Physical Activity and Sedentary Lifestyles (pp. 199-218). Berlin, Oxford: Peter Lang.

Rýgl, P. (2006). Tvorba školních vzdělávacích programů pro oblast tělesné výchovy na základní škole. /Educational programs on physical culture for elementary schools/. Česká kinantropologie, 10(2), 29-45.

Ř́hová, M., Skálová L., Komárek, L. (2007). Health Behaviour of Young People. School and Health 21 (pp. 125-139). Brno: Masarykova univerzita a Paido.

Rzewnicky, R. (2003). Health Enhancing Physical activity. Measurement and determinant of daily activity at home, work, travel, and leisure. Leuven: KU Leuven.

Sekot, A. (2006). Sociologie sportu /Sociology of sport/. Brno: Masarykova univerzita a Paido.

Sekot, A. (2008). Physical Activity Versus Obesity. Educatio Artis Gymnasticale, 3(3), 51-72.

Sekot, A., Brázdová, Z. (2008). Physical Activity and Nutrition as a Social Factors Influencing the Epidemic of Obesity. Studia Sportiva, 2(1), 112-125.

Sekot, A. (2010). Determinanty nadváhy a obezity: Pohybová aktivita a materiální prostředí /Determinants of overweight and obesity: Physical activity and material enviroment/. Zdraví, 1, 24-32. 
Slepička, P., Slepičková, I. (2002). Sport z pohledu české společnosti /Sport from the perspective of Czech society/. Česká kinantropologie, 1, 7-23.

Slepičková, I., Staněk, M. (2007). The impact of public administration reform on sport policy in Czech Republic. Local Sport in Europe. $4^{\text {th }}$ EASS Conference Proceedings.

Staněk, M., Flemr, L. (2007). The role of local authorities of Czech cities in support of sport: A case study of the capital city of Prague. Local Sport in Europe. $4^{\text {th }}$ EASS Proceedings.

Šeráková, H. (2007). Present views on obesity and overweight in common population of children and adults. School and Health. Brno: Masarykova univerzita a Paido.

AUTHOR'S ADDRESS:

\author{
Aleš Sekot \\ Masaryk University, Faculty of Sport Studies \\ Kamenice 5 \\ 62500 Czech Republik \\ Email: sekot@fsps.muni.cz
}

